ORIGINAL ARTICLES

\title{
EVALUATION OF PRIMARY SCREENING TEST FOR PLATELET HOMEOSTASIS IN PATIENTS WITH CHRONIC KIDNEY DISEASE
}

\author{
MD. NAZRUL ISLAM ${ }^{1}$, SHAH MD. SARWER JAHAN ${ }^{2}$, SHAH MD. BADRUDDUZA ${ }^{3}$, MD. ZAKIR HOSSAIN $^{4}$
}

\begin{abstract}
:
This observational study was done on 50 cases of predialytic chronic kidney disease (CKD) patients. The aim of the study was to determination of total platelet count and bleeding time, comparison of the platelet count and bleeding time with the severity of chronic kidney disease. The mean age of the patients was $41.22 \pm 2.0$ years, mean haemoglobin $4.96 \pm 0.32 \mathrm{gm} / \mathrm{dl}$, serum creatinine $430.74 \pm 11.92$ umol/L , platelet count $246.50 \pm 13.63 \times 10^{9} / \mathrm{L}$ and bleeding time were $4.13 \pm 0.28 \mathrm{~min}$ respectively. Thrombocytopenia $\left(<150 \times 10^{9} / \mathrm{L}\right)$ were found in $19(38 \%)$ cases. Bleeding time was prolonged ( $\left.>9 \mathrm{~min}\right)$ $6(12 \%)$ cases, among them only $4(8 \%)$ cases were thrombocytopenic. There was no significant relationship between platelet count and serum creatinine. No correlation was found between platelet count and bleeding time. No significant correlation was also found in Bleeding time and creatinine. Therefore, it can be concluded that platelet count is highly variable in chronic kidney disease and it is not a reliable screening test for bleeding diathesis in chronic kidney disease patients. Bleeding time is the best platelet function test that correlates clinical bleeding.
\end{abstract}

Key words: platelet, haemostasis, chronic kidney disease

\section{Introduction:}

Numerous haemostatic abnormalities associated with chronic kidney disease (CKD) ${ }^{1}$. Patients with Chronic kidney disease develops haemostatic disorder mainly in the form of bleeding diathesis . Hemorrhage occurs at cutaneus, mucosal and serosal sites. Retroperitoneal and intracranial hemorrhage also occur ${ }^{2}$. Bleeding diathesis in Chronic kidney disease is one of the indication for dialysis. Therefore it is important to know the exact platelet haemostatic status of the chronic kidney disease patients with bleeding diathesis for proper management.

Chronic kidney disease is associated with excessive bleeding for a variety of reason ${ }^{3}$. Pathogenesis of bleeding in chronic kidney disease is multifactorial in origin, there is no single explanation for this complex and confusing disorder ${ }^{4}$. Platelet dysfunction is probably the most consistent and important feature particularly platelet-platelet and platelet vessel wall interaction. Platelet dysfunction resulting from different adverse biochemical and hormonal effects associated with progressive uremia. There is defective membrane expression and activity of glycoprotein adhesive receptor complex causing both impaired platelet aggregation and adhesion to endothelium ${ }^{5}$. In addition, platelet volume and the circulation platelet mass are reduced in chronic kidney disease possibly due to reduction in thromboxane concentration or activity ${ }^{6}$. The mean platelet life span also reduce in advance chronic kidney disease $^{7}$.Bleeding time in chronic kidney disease patients not only depends on circulating platelet mass ,largely depends on its functional status.

Determination of total platelet count and bleeding time are the most popularly used primary screening test for bleeding diathesis. Among the different platelet function test, determination of bleeding time is the single most test that mostly correlates with the clinical bleeding and it is frequently used test for platelet function ${ }^{1,8}$. In this study total platelet count and bleeding time was determined in chronic kidney disease patients , comparison between platelet count and bleeding time and correlation between platelet count and bleeding time, platelet count and serum creatinine, bleeding time and creatinine were evaluated.

\section{Materials and Methods:}

This descriptive observational study was conducted in the Nephrology Unit of Rajshahi Medical College

1. Lecturer, Community Medicine, Rangpur Medical College, Rangpur, Bangladesh.

2. Assistant Professor, Department of Medicine, Rangpur Medical College Hospital

3. Associate Professor, Department of Pathology, Rajshahi Medical College, Rajshahi, Bangladesh.

4. Professor and Head, Department of Medicine, Rangpur Medical College and Hospital, Bangladesh.

Bangladesh J Medicine 2010; 21 : 55-57 
Hospital, Bangladesh from July, 2007 to December, 2007. A total 50 patients due to various causes were included in this study. There were 33 male and 17 female patients. The age ranges between 21-65 years. The inclusion criteria were predialytic chronic kidney disease patients with serum creatinine concentration $>177 \mu \mathrm{mol} / \mathrm{L}$ not taking anti platelet drug like aspirin/ clopedegrol or other and erythropoietin therapy . Chronic kidney disease patients having primary haematologial disorder, chronic liver disease and pregnancy were excluded from the study. All patients gave verbal consent prior to study entry.

After taken all aseptic precaution, $05 \mathrm{ml}$ venous blood was collected from antecubetal vein, two spot blood film were made and aliquots of blood send to the laboratory for biochemical and haematological analysis. Blood films were dried in the air and stained in with Leishman's stain for examination of smear under microscope. Total platelet count was determined by visual microscopic methods from the smear white blood cell (WBC) as reference $(\mathrm{PCW}=$ Platelet count based on WBC).Total platelet count $<150 \times 10^{9} / \mathrm{L}$ regarded as thrombocytopenia.Bed side bleeding time was determined following IVYs method. Bleeding time $>9$ min was regarded as prolonged bleeding time. Serum creatininine concentration was estimated by Alkaline cupric method. The results were recorded in printed form and subsequently analyzed. All data's were expressed as mean+ SD and SPSS windows version 12 software package was used for all statistical analysis.

\section{Results:}

A total of 50 Chronic kidney disease patients were included in the study. There were 33 male and 17 female with a male female ration of 1.9:1. The mean age of the patients was (41.22 \pm 2.0$)$ years( ranges between 22-65 yrs ) and the mean haemoglobin , serum creatinine concentration, platelet count and bleeding time were $4.96 \pm 0.32 \mathrm{gm} / \mathrm{dl}, 430.74 \pm 11.92$ $\mu \mathrm{mol} / \mathrm{L}, \quad 246.50 \pm 13.63 \times 10^{9} / \mathrm{L}, 4.13 \pm 0.28 \mathrm{~min}$ respectively ( Table-I).Out of these 50 patients thrombocytopenia were found in $19(38 \%)$ patients $(<150 \times 109 / 1)$. Bleeding time were found prolonged ( $>9$ $\min )$ in $6(12 \%)$ patients. Among those patients with prolonged bleeding time, thrombocytopenia were found in $4(8 \%)$ patients (Table-II). There was no correlation observed between platelet count and severity of Chronic kidney disease ( $r=0.079$, $p=<0.584$ ). No correlation between platelet count and bleeding time $(r=0.100, p=<0.49)$. No significant correlation also observed between bleeding time and severity of CKD ( $\mathrm{r}=0.189, \mathrm{p}=<0.189$ ) (Figure-1,2,3).
Table-I

Characteristics of 50 Chronic Kidney disease patients

\begin{tabular}{ll}
\hline Total number of patients & 50 \\
\hline Sex & 33 \\
$\quad$ Male & 17 \\
$\quad$ Female & $41.22 \pm 2.0$ \\
Mean age & $4.96 \pm 0.32 \mathrm{gm} / \mathrm{dl}$ \\
Mean haemoglobin & $430.74 \pm 11.92 \mu \mathrm{mol} / 1$ \\
Mean serum creatinine & $246.50 \pm 13.63 \times 10^{9} / 1$ \\
Mean Platelet count & $4.13 \pm 0.289(\mathrm{~min})$ \\
Mean bleeding time &
\end{tabular}

Table -II

Comparison between bleeding time and platelet count

\begin{tabular}{lcccc}
\hline Bleeding time & \multicolumn{5}{c}{ Platelet count $\times 10^{9} / \mathrm{L}$} \\
& $\begin{array}{c}<150 \\
(\mathrm{n}, \%)\end{array}$ & $\begin{array}{c}150-300 \\
(\mathrm{n}, \%)\end{array}$ & $\begin{array}{c}300-450 \\
(\mathrm{n}, \%)\end{array}$ & $\begin{array}{c}>450 \\
(\mathrm{n}, \%)\end{array}$ \\
\hline $\begin{array}{l}\text { Bleeding time } \\
\text { prolonged (>9 min) }\end{array}$ & $04(8)$ & $01(2)$ & $01(2)$ & 0 \\
$\mathrm{n}=6$
\end{tabular}

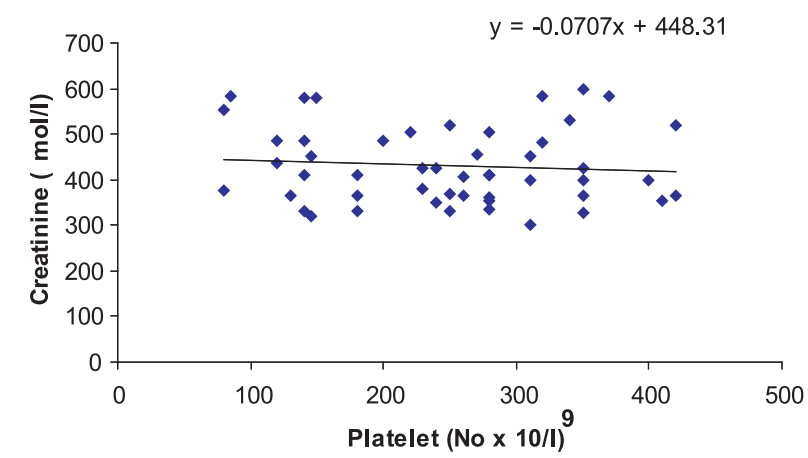

Fig.-1: Scattered diagram showing no correlation between platelet count and creatinine

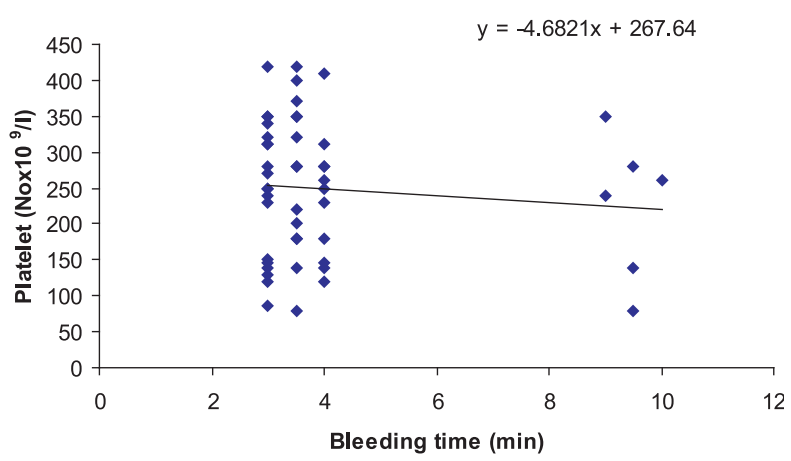

Fig.-2: Showing no correlation between platelet count and bleeding time. 


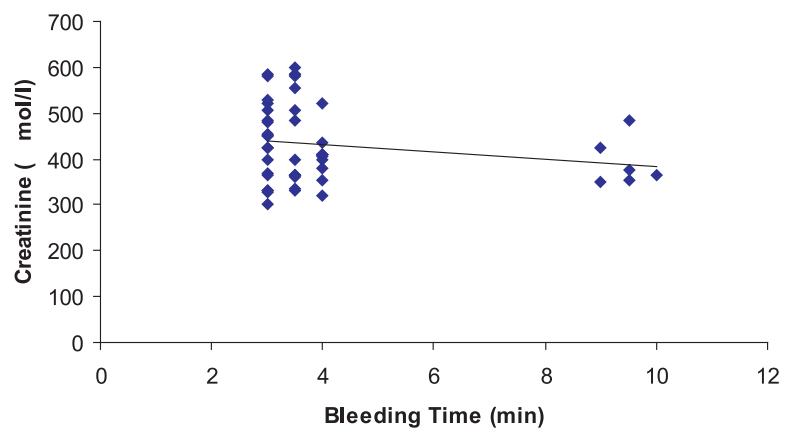

Fig.-3 : Scattered diagram showing no correlation between bleeding time and creatinine.

\section{Discussion:}

The frequency of thrombocytopenia in chronic kidney disease patients is controversial $^{9}$. Platelet count is highly variable in chronic kidney disease patients , largely depends on the etiopathogeneis of the disease. The greatest role in the development of haemostatic disturbences in patients with chronic kidney disease is ascribed to the Platelet ${ }^{10}$. Bleeding tendency in chronic kidney disease patients not only depend on platelet count mostly depends on the platelet functional status. Patients with advanced chronic kidney disease suffer from complex haemostatic disorders. Ureamic patients show a bleeding diathesis that mainly due to abnormalities of primary haemostasis; in particular platelet dysfunction and impaired platelet vessel wall interaction ${ }^{11}$.

In present study, out of 50 predialytic chronic kidney disease patients, thrombocytopenia was found in $38 \%$ cases $\left(<150 \times 10^{9} / \mathrm{L}\right)$. This finding contradict with that of Akinsola et al, Talwar et al and Aboo et al ,where they found thrombocytopenia in 7.6\%, 52\% and $29.3 \%$ cases respectively $12,13,14$. Small variation may be possible due to difference in the method of determination of platelet count. But this contradiction justified that platelet count in chronic kidney disease patients is highly variable.

Out of 50 chronic kidney disease patients, bleeding time was found prolonged (>9 $\mathrm{min}$ ) in $6(12 \%)$ cases, among them, thrombocytopenia was found in $4(8 \%)$ cases. This findings are in consistent with that of Akinsola et al, who found prolonged bleeding time in $25.6 \%$ cases where $7.6 \%$ cases were thrombocytopenic ${ }^{12}$.

There was no correlation observed between platelet count and serum creatinine. No correlation between platelet count and bleeding time. No significant correlation also observed between bleeding time and serum creatinine (Figure-1,2,3). This findings are consistent with that of Akinsola et al who found no correlation between platelet count and bleeding time and between bleeding time and serum creatinine ${ }^{12}$.

\section{Conclusion:}

Therefore, it is concluded that though determination of total platelet count is the first line screening test for platelet haemostatic disorder, it is not a absolute reliable parameter as it is highly variable in chronic kidney disease patients. It is also concluded that bleeding time is the best platelet function test that reflects both qualitative and quantitative platelet haemostatic abnormalities and should considered first line screening test for bleeding diathesis associated with chronic kidney disease patients in developing countries.

\section{References:}

1. Jubelirer SJ. Haemostatic abnormalities in renal disease. Am J Kidney Dis. 1985 May;5(5):219-25.

2. Kaw D, Malhotra D, platelet dysfunction in endstage renal disease. Semin Dial.2006 JulAg; 19(4):317-22.

3. HO SJ, Gemmell R, Brighton TA. Platelet function testing in uraemic patients. Haematology.2008 Feb;13(1):49-58.

4. Bengnin A. et al. Reversible activation defect of the plateelt Glycoprotein IIB-IIIA complex in patients with uraemia. American Journal of Kidney disease. 1993;22.668-676.

5. Huraib S, Gader AM, alMomen et al. Haemostasis. 1995 Nov-Dec;25(6):299-394.

6. Coresh J, Astor BC, Green T et al. Prevalence of chronic kidney disease and decreased kidney function in adult US population: Third National Health and Nutrition Examination Survey. Am J Kidney Dis.2003;41(1):1-12.

7. Lusvarghi E. et al. Evaluations of platelet kinetics in chronic renal failure (conservative and regular dialysis treatment). Haematologica.1979;64:747758.

8. Lind SE. Prolonged bleeding time. Am J Med.1984 Aug;77(2): 305-12.

9. Gafter U, Bessler H, malachi T, Zevein D, Djaldetti M, Levi J. Platelet count and thrombopoietic activity in patients with Chronic renal failure. Nephron. 1987; 45(3): 207-10

10. Krawczyk W, Dmoszriska A, Sokolowska B. Evaluation of platelet haemostatis in patients with chronic renal failure.MiadLek.1994;47(3-4):93-9.

11. Boccardo P, Remugi G,Galbusera M. platelet dysfunction in renal failure. Semin Thromb Haemost. 2004;30(5): 579-89.

12. Akinsola A, Durosinmi MO and Akinola NO. The haemato-logical profile of Nigerians with chronic renal failure. Afr J Med Med Sci.2000; 29(1);13-6.

13. Talwar VK, Gupta HL and Shasinarayan. Clinicohaematological profile in Chronic renal failure.J Assoc Physicians India.2002 Feb;50:22833.

14. Aboo O, Seedat YK. Thrombocytopenia in renal failure in developing country.Nephron.1987; $45(3): 228-33$. 